\title{
Delirios de descomposición en Samanta Schweblin, Daniela Tarazona y Mariana Enríquez ${ }^{1}$
}

Betina Keizman $^{2}$

Resumen. El presente artículo propone explorar las corporalidades en descomposición en algunas ficciones que ensayan formas de transformación y tránsito de los cuerpos (reencarnación, mutación, deslizamiento desde y hacia la animalidad). En franca oposición al dogma neoliberal de que no hay alternativas, estas ficciones pergeñan formas delirantes de vida, en términos de inmortalidad de la especie, de evolución transhumana y/o por la acción de colectivos disidentes. En particular, la exploración de maternidades o de gestaciones alternativas posiciona las ficciones ante una responsabilidad en relación con "los que vendrán" que transciende ampliamente las fronteras del cuidado restringido al ámbito familiar y postula en su lugar derechos-cuidado y ética con alcances colectivos.

Palabras clave: transhumanismo; antropoceno; ficciones recientes.

\section{[en] Delusion of decomposition in Samanta Schweblin, Daniela Tarazona and Mariana Enríquez}

Abstract. This essay explore the decomposing corporalities in some fictions that tries forms of transmutation and transit of the bodies (reincarnation, mutation, gliding from and towards the animality). In open opposition to the neoliberal dogma that there are no alternatives, these fictions features delusional forms of life, in terms of the immortality of the specy, of transhuman evolution and / or by the action of dissident unions. Typically, the exploration of maternities or alternative pregnancies situates the fictions in front of a responsibility related to "those who will come" that transcends widely the borders of the attention restricted to the family frame and postulates in its place rights-care and ethics in a collective level.

Keywords: transhumanism; anthropocene; recent fictions.

Sumario: 1. Introducción. 2. El capitalismo sin rescate. 3. Lo que está sobre la piedra. 4. Los mundos pegajosos de Mariana Enríquez. 5. Delirios imaginativos versus imaginaciones devastadas.

Cómo citar: Keizman, B. (2021) Delirios de descomposición en Samanta Schweblin, Daniela Tarazona y Mariana Enríquez, en Anales de Literatua Hispanoamericana 50, 273-285.

\section{Introducción}

Propongo explorar cómo concibe la noción de sujeto, muchas veces en relación con una corporalidad en descomposición, un conjunto de narrativas recientes que ensayan formas de transformación y tránsito de los cuerpos (reencarnación, mutación, deslizamiento desde y hacia la animalidad). Me centraré en algunas obras de Samanta Schweblin, Daniela Tarazona y Mariana Enríquez, pero podría considerarlas en un marco más amplio, que tampoco quiero perder de vista. ${ }^{3}$

\footnotetext{
${ }^{1}$ Este trabajo forma parte del proyecto de investigación regular Fondecyt n 1170129: "Perspectivas ampliadas: formas de vida, comunidad y poética en las narrativas contemporáneas en Chile, México y Argentina."

2 Universidad Alberto Hurtado. Argentina.

E-mail: bkeizman@uahurtado.cl

${ }^{3}$ A este corpus mayor contribuyen, entre otros, Fruta podrida de la chilena Lina Meruane, La comemadre del argentino Roque Larraqy, Vidas perpendiculares de Alvaro Enrigue, El huésped de Guadalupe Nettel, Ricardo Nixon Schooll de Cristian Geisse, Los multipatópodos de Yosa Vidal, Papeles falsos de Valeria Luiselli y Perros héroes de Mario Bellatin.
} 
¿Qué tienen en común estas narraciones? En principio, y sin atender a las particularidades de cada caso, presentan subjetividades y cuerpos en tránsito que se corresponden con identidades también fluidas y provisorias, las que a su vez corroboran patrones conformes al capitalismo global del presente. Lo distintivo de estas nuevas categorías de identidad se revela, en particular, al contrastarlas con el carácter esencialista de la identidad humana tal como fuera entendida en épocas precedentes. Mucho más que una identidad rígida y sostenida a lo largo de la vida, aquella que hasta el siglo pasado había sustentado la noción de sujeto productivo y ético, la identidad contemporánea se nos presenta bajo un ropaje susceptible de transmutación, es más, que exige innovarse al ritmo de un mercado que valora en primer grado las capacidades de reconversión.

Merece mención, por otra parte, que los relatos de mutación, fantasmas y reencarnaciones tributan a una extensa genealogía cuyas raíces calan en la cultura popular y que luego fueron reactivadas por el gótico literario. Sin embargo, la relativización y fluidez de las identidades contemporáneas, y la poderosa corriente motivada por el afán de desmaterializar lo humano en pos de su tratamiento como sistema de información, alerta sobre los alcances específicos que estos imaginarios están agitando en sus versiones más recientes. En suma, aun estableciendo ciertas continuidades temáticas, de género o incluso de tratamiento, estas narraciones de las que me ocupo se desmarcan de narraciones precedentes, que fueron punta de lanza en el cuestionamiento y ampliación de dinámicas hegemónicas de binarismo moral, de género y/o psicológico. ${ }^{4}$ En fin, estos relatos recientes actualizan con todos los honores una tradición de larga data aunque ciertamente progresan sobre terrenos diferentes. En algunos, las exploraciones identitarias o de corporalidades múltiples conviven con preocupaciones ecológicas en relación con el antropoceno (definido a partir del manifiesto impacto global de las actividades humanas sobre los ecosistemas terrestres), y la mayoría expresa una perspectiva profundamente pesimista sobre el futuro, una percepción que en Distancia de rescate, la novela de Schweblin (2014), para dar un ejemplo, se acentúa cuando descubrimos que las víctimas predilectas de una inmolación colectiva son niños.

La utopía de ser alguien diferente, de nacer de nuevo, de poder devenir otro -todo lo que implica la desestabilización identitaria- tiene indudables efectos estimulantes si admitimos el grado de libertad y de creación de sí que invoca como ejercicio y como postural vivencial. Empero, podría considerarse que esta utopía de la transformación identitaria y corporal también favorece una dinámica perversa en cuanto estimula la relativización de las condiciones políticas o cuanto menos abre la puerta a una vía de superación individual a las contradicciones sistémicas. Zigmunt Bauman advierte, al respecto, que los "riesgos y las contradicciones siguen siendo producidos socialmente; sólo se está cargando al individuo con la responsabilidad y la necesidad de enfrentarlos" (Bauman, 2004: 40). Como consecuencia de esta tensión, las vías ficcionales ponen en movimiento dos fuerzas opuestas: en un lado, la potencialidad imaginativa de las identidades múltiples, una descomposición del sujeto que podría dar lugar a nuevas formas de lo humano y de la colectividad; y por otro lado, modos de vida huidizos que se forjan producto de las presiones sobre el individuo contemporáneo, y que desembocan en desenlaces angustiados, ritmados mucho más por lo que se pierde que por lo que pudiera adquirirse en una segunda instancia.

El incremento de narrativas que ensayan cambios de cuerpos y fluctuación de identidades expresa una desestabilización identitaria que, acordemos, podría ser la propia de una sensibilidad contemporánea, pero asimismo manifiesta una percepción de lo humano proyectada independientemente de su materialidad orgánica, impulsada por un imperativo de conexión que prescinde de barreras espaciales y materiales para optimizar la productividad. No es de extrañar que cuando las narraciones avanzan en el terreno de la utopía y la potencialidad, exacerban modalidades ya vigentes de la desmaterialización contemporánea: el incremento del trabajo virtual o la aceleración de las transmisiones de imagen, sonido e información que involucran una autonomía hasta hace poco inimaginable de las capacidades humanas en relación con el cuerpo y su orden espaciotemporal. Tampoco se trata de una deshumanización o tecnologización de lo humano, tal como señala Paula Sibilia, en el modelo de hombre como información, "podría parecer que el materialismo se ha extendido hasta sus últimas consecuencias" (Sibilia, 2006: 96) pese a que hay, de hecho, "un privilegio del polo inmaterial del viejo dualismo cartesiano, potenciando la mente y descartando el cuerpo como un mero obstáculo demasiado material" (Sibilia, 2006: 96). Es decir que también estas tensiones entre cuerpo, mente

${ }^{4}$ Estoy pensando, en particular, en el gótico del siglo XIX y en novelas como Frankenstein o El extraño caso del doctor Jekyll y Mister Hyde y, en el ámbito latinoamericano, en algunos cuentos de Leopoldo Lugones y, mucho más recientes, de Antonio Di Benedetto. 
y sujeto, tecnologías y modos de identidad subyacen de un modo decisivo en las narraciones que propongo explorar.

\section{El capitalismo sin rescate}

Hasta la publicación de la novela Distancia de rescate, la argentina Samanta Schweblin era una reconocida cuentista, con múltiples premios internacionales, se la considera cultora de una literatura de lo extraño, un nicho narrativo afín a las obras de Mariana Enríquez y Daniela Tarazona. ${ }^{5}$ También Distancia de rescate honra el mismo registro cuando narra en clave de relato de fantasmas, la muerte y la enfermedad de niños y adultos debido a la exposición a los agroquímicos en un sector rural sojero. El único y radical escape de esta condena a muerte reside en la intervención de la curandera del pueblo, quien libera los cuerpos enfermos (por lo menos en el caso de los niños) y hospeda sus "espíritus" en otros cuerpos, en uno o en varios, en una política de migración de almas que se vislumbra como la única solución desesperada frente la acción invisible del glifosato.

En escasas 125 páginas, Schweblin trenza la complejidad de un argumento que escapa a la alegoría y que se amplifica drásticamente en un juego de redes que se intersectan. Se trata de una secuencia narrativa que ramifica el impacto de los agroquímicos y la búsqueda febril de beneficios asociado a las nuevas tecnologías transgénicas y lo liga a políticas de familia, el rol paterno y materno, a la viabilidad de modelos económicos y sociales y al agenciamiento, o falta de agenciamiento, de las comunidades. La dificultad para discernir e identificar los problemas que aquejan a los protagonistas y a la comunidad de la novela desemboca, por fin, en la fluidez de los cuerpos para disolverse y transmigrar gracias a una implícita disponibilidad del sujeto como secuencia informativa y vida afectiva. Es válido preguntarse qué es precisamente lo que transmigra ¿El recuerdo, el pasado, los afectos, la personalidad, las experiencias?: no lo sabemos. Desde estos presupuestos narrativos que incluyen algún grado de salvación, pero también una pérdida evidente, la novela se expande hacia un cuestionamiento sobre la maternidad, las relaciones intrageneracionales y las responsabilidades éticas en que estas relaciones se asientan:

El efecto va y viene, están intoxicadas.

Sí. ¿Y entonces por qué nos dan algo para insolación?

Porque la enfermera es una mujer muy tonta.

Después me vuelvo a dormir.

Varias horas.

Sí. Pero el hijo de la enfermera, los chicos que vienen a esta aula, ¿son chicos intoxicados? ¿Cómo puede una madre no darse cuenta?

No todos sufrieron intoxicaciones. Algunos ser nacieron envenenados, por algo que sus madres aspiraron en el aire, por algo que comieron o tocaron (Schweblin, 2014: 104).

Schweblin organiza y transmite al lector un entretejido obscuro de niveles del relato que remiten a fenómenos complejos, de algún modo confusos, pero cuya evidencia se ha vuelto indisimulable. El antropoceno opera como un cuestionamiento retrospectivo de los fundamentos del orden del progreso sobre los que se erige el pensamiento de la modernidad, y como tal ha puesto en evidencia fenómenos complejos (desde procesos migratorios a degradaciones del ecosistema), que impugnan la disociación efectiva entre discurso, naturaleza y política. ${ }^{6}$

Distancia de rescate organiza y expone esta complejidad gracias a un artilugio formal: un diálogo. La novela es un diálogo entre Carla, la madre de Nina, también intoxicada y al borde de la muerte, y el espíritu fantasmal de David, otro niño enfermo que ha sido "transmigrado". En un orden casi socrático, ese diálogo, que es tan extenso como el libro mismo, orienta a la moribunda hacia el descubrimiento de los hechos que

\footnotetext{
${ }^{5}$ Eludo en este punto una discusión de clasificación genérica, me basta destacar que las tres escritoras han desarrollado su trabajo, en particular en los casos de Enríquez y Schweblin, en el terreno siempre híbrido del género gótico o fantástico, en fin, de lo que aquí prefiero denominar lo extraño.

${ }^{6}$ En "Clima e historia: cuatro tesis", Dipesh Chakrabarty propone: 1. Que las explicaciones antropogénicas del cambio climático implican el colapso de la antigua distinción humanista entre la historia natural y la historia humana; 2 . Que la idea del antropoceno, la nueva era geológica en la que los seres humanos existen como fuerza geológica, matiza profundamente las historias humanistas de la modernidad/globalización; 3 que la hipótesis geológica relativa al antropoceno nos obliga a relacionar las historias globales del capital con la historia de los humanos como especie y, finalmente, que el entramado de la historia de la especie y de la historia del capital es un proceso de exploración de los límites de la comprensión histórica (Chakrabarty, 2009: 54-67).
} 
protagonizó y de aquellos que no alcanzará a ver, posteriores o inmediatos a su muerte, pero que también vigila gracias a una mirada panóptica, escindida de su cuerpo yacente. El "nosotros" que aparece en ese diálogo es el de los enfermos, pero también el de David en el hospital habitando su propio cuerpo, a la vez que fraccionado en los cuerpos de otros:

Hay algo un poco más allá sobre la calle, llegando a la esquina. Voy más despacio, y entrecierro más los ojos. Es difícil, David. Duele muchísimo.

¿Somos nosotros?

¿Quiénes?

Los que cruzan la clase.

Es un grupo de gente. Freno el coche y los veo, cruzan a centímetros del coche. ¿Qué hace tanta gente junta esta hora? Hay muchos chicos, casi todos son chicos. ¿Qué hacen cruzando todos juntos, a esta hora?

No llevan a la sala de espera. Ahí nos dejan antes de que el día empiece. Si tenemos un mal día nos regresan antes, pero por lo general no volvemos a casa hasta la noche.

Una señora en cada esquina vigila que el cruce se seguro.

Es difícil cuidar de nosotros en las casas, algunos padres ni siquiera saben cómo hacerlo (Schweblin 2014: 107).

En tal sentido, el hospital se vislumbra como una suerte de purgatorio en donde ese diálogo reiterado alcanzará un desenlace, sea la comprensión, la muerte, o ambos. El diálogo desacelera, el diálogo divaga, se confunde, alcanza el juicio con la contribución de interlocutores diversos, en ese sentido todo diálogo desliza en la escritura una dimensión de oralidad, que a su vez repone una detención en el sistema de progreso acelerado que rige el mundo contemporáneo (remito al trabajo de Harmut Rosa de 2011 en "Aceleración social: consecuencias éticas y políticas de una sociedad de alta velocidad desincronizada"). Además, como primera tecnología comunicativa, en esta novela el diálogo recupera su peso pedagógico. La voz propedéutica de David guía la conversación, que también remeda una sesión psicoanalítica en que la moribunda repasa actos propios y ajenos con el propósito de adjudicarles un sentido. La pulsión pedagógica, las indicaciones y las preguntas de David fuerzan la mirada de su interlocutora moribunda a atender tal y cual punto, y a descartar otro, anticipando en la desmaterialización de esa perspectiva (recordemos que Carla esta seminconsciente en una cama de hospital), la desmaterialización de los cuerpos y la transmigración de los espíritus que el relato procesa como única solución para el sistema y para los organismos enfermos. El vínculo que debe entender la moribunda es el mismo que debe comprender el lector, en una progresiva visibilización de aquello que vibra por debajo de la apariencia bucólica del campo cultivado y que se resume en los efectos devastadores de las agriculturas del postcapitalismo que, para optimar a cualquier precio los beneficios, inmolan territorio, poblaciones y futuro.

Como paradoja, este proceso de entendimiento surge de un diálogo invertido en que un niño transmite su comprensión al adulto, que solamente en su condición de moribundo podría recibir tal enseñanza. Lo que la novela subraya es la enorme dificultad para aprehender el desastre, aprehender en el sentido de asimilar, apropiarse, casi materialmente, de un conocimiento. La insistente reflexión metatextual sobre la que se erige el relato comunica - es nuestra tesis- este esfuerzo extremo por transmitir redes cognitivas, vinculares y afectivas que permitan aprehender los alcances de esos fenómenos que dependen tanto de la acción de los sujetos como de la acción de la naturaleza, los objetos y la tierra. Se expone así la dificultad de forzar otra mirada que active la narrativa de los sucesos a contrapelo de los relatos oficiales que proponen la cuestión como una balanza de costos-beneficios que finalmente justifica las llamadas zonas de sacrificio. ${ }^{7}$ En ese sentido, el puntal que refuerza nuestra comprensión de la novela reside en que las problemáticas que desfilan constituyen un horizonte de saberes que nosotros, los lectores, compartimos por ser habitantes del presente. En suma, el niño fantasma le explica a la moribunda, y a nosotros, aquello que ya sabemos, los desastres ecológicos debidos a las fumigaciones e intervenciones agroquímicas en los procesos de producción de alimentos. Y, en segundo plano, la narración transmite el pánico por nuestra propia incapacidad en la generación de acciones que desvíen o amortigüen el desastre anunciado.

\footnotetext{
${ }^{7}$ Al respecto, Isabelle Stengers (2007) discute en En tiempos de catástrofes. Cómo resistir a la barbarie que viene las dificultades epistemológicas, estratégicas y prácticas para ejercer lo que ella denomina "prestar atención", es decir, ser capaces de detectar los problemas y poder abordarlos en su justo valor.
} 
Una pregunta fundamental es hasta qué grado estas ficciones latinoamericanas también dan cuenta de una fluctuación importante en las relaciones entre lo local y lo global. Esta consideración subyace al argumento de la novela de Schweblin, de algún modo deslocalizado, porque pese a que lo que se narra sucede en una geografía específica, intrínsecamente, las narraciones exploran interrelaciones que desbordan fronteras geográficas, así como compartimentaciones entre lo propiamente político y lo personal, la naturaleza y lo sociedad, lo individual y lo colectivo. ${ }^{8}$ Si bien, en el caso de Samanta Schweblin el germen del relato se nutre de un estado de urgencia que golpea las regiones rurales de Argentina, el tratamiento de la narración contribuye a extrapolarlo hacia un marco de preocupaciones deslocalizadas. ${ }^{9}$

En relación con esta localización "deslocalizada", resulta relevante que la bruja o curandera que en la novela opera el cambio de los cuerpos sea, justamente ella, extrañamente transcultural. Pese a que su intervención apela a un saber indígena-originario, la mujer de la novela de Schweblin está escindida de cualquier contexto cultural y comunitario, y probablemente este aislamiento refuerza el carácter, también transcultural, de su mediación. ${ }^{10}$ Esta descontextualización despolitiza la injerencia de esos otros saberes, aporta otra opción, sí, pero una opción que termina desligada de su origen.

Retomando el corpus tácito que presenté en el inicio de este artículo, notamos que la lógica de tránsito y de bifurcación altera las relaciones entre lo local y lo global. Esta lógica desplaza las ficciones de lo local porque pone en escena problemas y disyuntivas que son globales. Pero asimismo opera un repliegue sobre lo propio, donde el rescate de los niños y el entorno familiar que inicialmente propone Distancia de rescate se reduce y se estrecha, al final, al vínculo madre-hijo. ${ }^{11}$

Pero esta delimitación familiar del argumento de Distancia de rescate luego se amplifica a un grado inimaginable, que incluso trasciende lo colectivo o comunitario (¿cómo constituir un "entre-nos" si el yo y el nosotros se diluyen en un estado incorpóreo?). La distancia de rescate, la migración de los cuerpos y las prácticas de "atadura" que, en el desenlace, el niño fantasma dispone para sostener-unir-ensamblar lo que está en proceso de disolución, exponen bien el doble movimiento que juega esta narración. Los personajes enfrentan un dilema perverso: la condición de supervivencia exige abandonar las limitaciones individuales del sujeto y esta vida postmortem, que en el desenlace se insinúa como una especie de panconciencia colectiva, genera, por qué no decirlo, una importante dosis de ansiedad. ${ }^{12}$ Para sobrevivir hay que ser otro, abandonar el cuerpo en una excepcional forma de escape, siempre provisoria, a las condiciones económicas, políticas y sociales que amenazan lo humano:

Sólo entonces mi marido enciende el motor, baja la lomada y toma el camino de ripio. Siente que esa perdió demasiado tiempo. No se detiene en el pueblo. No mira hacia atrás. No ve los campos de soja, los riachuelos entretejiendo las tierras secas, los kilómetros de campo abierto sin ganado, las villas y las fábricas, llegando a la ciudad. No repara en que el viaje de vuelta se ha ido haciendo más y más lento. Que hay demasiados coches, coches y más coches cubriendo cada nervadura de asfalto. Y que el tránsito está estancado, paralizado desde hace horas, humeando efervescente. No ve lo importante: el hilo finalmente suelto, como una mecha encendida en algún lugar; la plaga inmóvil a punto de irritarse. (Schweblin, 2014: 124)

Desde esta perspectiva, la oralidad que regula la narración, y que hemos comentado como este diálogo de aprendizaje que orienta Daniel, involucra asimismo una ampliación del origen de la voz y la deslocalización de una existencia que se escapa del cuerpo. Así como la voz proviene de un no-cuerpo, también la mirada se

${ }^{8}$ Sin embargo, tal como señala Jens Andermann (2018) en Tierras en trance, Latinoamérica ha sufrido como ningún otro territorio las consecuencias llamadas antropocénicas de los capitalismos extractivos, cuyos ecos son transmitidos por un verdadero corpus de reflexiones teóricas y producciones creativas en la cultura latinoamericana que se remontan a principios de siglo XX, que Andermann denomina "historias del antropoceno".

${ }^{9}$ Los impactos en la salud debido a la contaminación en las llamadas "zonas de sacrificio" tiene en territorio latinoamericano un carácter urgente. Mientras escribo esto, en el 2018, se ha dado el caso de Quintero y Puchuncaví en Chile, y el impacto de agrotóxicos, en particular el uso del glifosato al que remite la novela de Schweblin, mantiene un historial de denuncias consistentes por más de una década en Argentina.

${ }^{10}$ Recuerda, en su contexto, el papel del vudú en las películas norteamericanas de posesión de cuerpos, donde también se reiteran estas épicas de cuerpos poseídos y fuerzas desatadas en los suburbios y periferias.

11 “Salvar los niños, salvar la familia” es un argumento que Helen Hester (2018) cuestiona enfáticamente en Xenofeminismo. Tecnologías de género y políticas de reproducción porque le atribuye una perspectiva conservadora en relación con la uniformidad del futuro a salvar, lo que ella identifica como niños heteronormativos. Es una observación aplicable al relato de Schweblin en donde los niños en jaque, un niño y una niña, representan la faz inversa de los niños deformes y disimulados puertas adentro en el pueblo.

${ }^{12}$ Bajo una consideración afín, Rosi Braidotti discute las posturas que perpetúan el "hábito filosófico de tomar la mortalidad o la finitud como el horizonte transhistórico para los debates de la "vida"" (64): "Me permito discrepar de la tendencia que favorece el despliegue del problema bios/zoé en el horizonte de la muerte, en el estado liminal de la no vida o en la economía espectral de lo nunca muerto. Prefiero, en cambio, poner el acento en los poderes generativos de zoé retornando a la ontología espinoziana defendida por Deleuze y Guattari (1972 ${ }^{\mathrm{a}}$, 1980) (64). 
libera del sistema ocular. En suma, voz y mirada se modulan bajo condiciones de ubicuidad que extreman la experiencia descarnada de la única "solución" disponible. No es menor que el título de la novela se refiera al parámetro con que la madre protagonista regula los riesgos que corre su hija, su "distancia de rescate". Una teoría y una distancia que fracasan, entre otros motivos por la propia acotación del cuidado que propone, un cuidado de uno a uno que desconoce la extensión y la globalidad de los peligros que enfrenta. Evidentemente, la madre no ha prestado atención porque ella misma es prisionera del individualismo de la protección que ofrece.

\section{Lo que está sobre la piedra}

El animal sobre la piedra, publicada originalmente en 2008, es un relato de mutación que arriesga otro grado de descorporización, en este caso, avanzando sobre el terreno de una narrativa transhumana. La novela de Daniela Tarazona narra una mutación corporal, un devenir animal que también se tensiona con un devenir mujer ya que la experiencia del personaje que muta es, específicamente, la experiencia de una gestación. En la novela, la "protagonista" viaja desde una ciudad hacia una región de playa, donde podrá concretar su transformación en reptil, probablemente un camaleón. Sometida a cambios corporales que los demás parecen ver y no ver, la narradora registra por escrito la crónica de esta mutación mientras es acogida por un compañero, un hombre envejecido cuya mascota es un oso hormiguero nombrado Lisandro. De algún modo, esta novela responde la pregunta que formula Jean-Luc Nancy (2007) en 58 indicios sobre el cuerpo, Extensión del alma con relación a cómo narrar la experiencia del cuerpo y de sus límites, una exploración a partir de la certeza de que no tenemos o habitamos un cuerpo, sino que "somos un cuerpo". El relato de la protagonista, quien se autoinstruye como testigo de su propia mutación, surge de un presupuesto fundamental: ella es el sujeto, objeto y testigo de esa transformación. En tanto objeto y sujeto, la narración explora ese adentro-afuera del devenir animal: "mi cuerpo sabe que comienza un ciclo evolutivo" (Tarazona, 2011: 33), afirmará.

Tal como indica Nancy (2007) en su prefacio a la edición española de 58 indicios sobre el cuerpo, es un error considerar como independientes la res extensa y la res cogitans, la cosa extensa y la cosa pensante porque no hay dimensiones exteriores e interiores, tampoco hay sentimientos o sensaciones independientes del cuerpo. Efectivamente, Tarazona se ubica en el punto mismo de esta relación, donde el pensamiento se activa en presencia de las propias entrañas y vísceras: "Quiero explicar más cosas; por ejemplo, la certeza de mis vísceras: siento que tengo interior. Las tripas rozan las paredes de mi abdomen, el corazón se recarga sobre los pulmones de una manera suave" (Tarazona, 2011: 42). Adherida a su corporalidad, el personaje mutante transita hacia una conciencia que se expresa en una omnisciencia ampliada, una "voz de especie" que tanto la orienta sobre su nuevo estado como le provee referentes sobre su entorno. El personaje es un cuerpo y es una voz, sin separación posible entre una y otra: "El alma está extendida por todas partes a través del cuerpo, dice Descartes, está enteramente por todas partes a lo largo de él, en él mismo, insinuada en él, escurrida, infiltrada, impregnante, tentacular, insuflante, modelante, omnipresente." (Nancy, 2007: 6)

La mutación de la protagonista se somete a un orden narrativo previsible cuando transita transformaciones que amplían su campo perceptivo hacia la animalidad: oído más fino, sensibilidad olfativa, nueva elasticidad, secreción de veneno y de olores, nuevas condiciones de la mirada. Por el contrario, lo que corresponde a la pérdida del raciocinio y de la capacidad simbólica, que también sería esperable en un proceso de animalización, resulta escamoteado en la novela: cuando ya no consiga escribir, o hablar, será su compañero quien escriba en su nombre. ${ }^{13} \mathrm{Al}$ mismo tiempo, la introducción de imágenes y dibujos que reproducen visualmente sus transformaciones corporales (el pellejo que pierde, las protuberancias que le nacen) iluminan los estadios de su progresiva evolución. Lo que se expresa, radica, finalmente y de una manera preponderante, en una mutación que es perceptiva y cognitiva, simultáneamente.

Voy a explicar lo que estas alturas veo en el mundo. Las cosas exteriores no son como las sabía. Los objetos son transparentes, como si fuesen hechos del aire, su consistencia no es la que conocía. Por ejemplo: las sillas están detenidas en el vacío. No hay en los objetos un comienzo y un final, se encuentran unidos sin que pueda

\footnotetext{
${ }^{13}$ No establezco aquí una lectura amplia de las implicancias del devenir animal en el campo de la biopolítica o de las definiciones de lo humano. A tal efecto, remito a George Deleuze (2002), Gabriel Giorgi (2014) y Jens Andermann (2011).
} 
definir unos y no otro. Quizá mis primeros atisbos sobre esta situación ocurrieron cuando mis párpados adquirieron transparencia.

Decir lo que dije de las sillas es falsear la imagen que me proyectan, porque las sillas son parte del suelo, la mesa y el espacio. No puedo explicar lo mejor, me rindo ahora (Tarazona, 2011:78).

Sin embargo, la narración de este devenir animal no es lo más interesante del libro de Tarazona porque la mutación sigue una lógica predecible cuando se centra en las capacidades o habilidades que se retiran o que se adquieren. La vuelta de tuerca de la narración consiste, no obstante, en que la mutación que se narra no es exclusiva, no compete solamente a la protagonista, por el contrario, la experiencia que vive el personaje irradia en su comprensión del mundo como un mundo que también está mutando, que, muy probablemente, está mutando desde siempre. Es gracias a la transformación del orden temporal que el personaje accede a percibir estos procesos intangibles. Su compañero le dice lo siguiente: "Eres un animal prehistórico y estás viendo transcurrir el tiempo que nadie más ve" (Tarazona, 2011: 38). En efecto, cuando el personaje deviene reptil sufre episodios de parálisis, entre otros trastocamientos en sus tiempos vitales y perceptivos: una siesta que dura meses y una experiencia del tiempo que bien puede contraerse o ampliarse en estaciones o períodos de frio, calor o lluvias que regulan su experiencia.

La confusión narrativa que se genera en relación con el orden de los sucesos entorpece cualquier posible imposición de una cronología de la mutación, pero, reitero, también es la mutación misma la que perturba la temporalidad y en definitiva supone la aceleración de un proceso de evolución de especie que, "normalmente", sería mucho más lento. En el capítulo XI, cuyo título es "Lo que olvidé", se enuncian hitos de posibles pérdidas de memoria del personaje: su estancia en el hospital, el viaje en tren y el modo en que llegó a la playa en donde conoció a su compañero. Estas pérdidas de memoria desorganizan la cronología narrativa al tiempo que contribuyen a expresar la experiencia de alguien que deja de ser humano en el abandono de su subjetividad y, por lo tanto, de sus recuerdos y de su propia historia. Como resultado, El animal sobre la piedra es un relato tanto proyectivo como de inversión temporal ${ }^{14} \mathrm{El}$ ser que muta regresa a su ambiente, o a algún tipo de ambiente rocoso, en la arena, que lo retrotrae a una época "prehistórica", en la medida que invierte el proceso de aislamiento y de artificialización del entorno que han sufrido tanto humanos como animales. Si, como señala Berger (2001) en “¿Por qué mirar a los animales?”, el animal liga al hombre con su origen, en este relato la anulación del tiempo se da en un plano en que evolución y regresión coinciden. Este fenómeno solo puede producirse cuando el tiempo histórico se erradica, cuando en ausencia de persona humana y de tiempo histórico, futuro y pasado devienen en experiencia indiferenciada. Por eso, tanto la mutación corporal como la temporal desbordan la experiencia de la mujer-reptil y reubican otros procesos, la muerte y el envejecimiento (del compañero y del oso hormiguero), por ejemplo, en un orden de mutaciones que, asimismo, involucra todo lo viviente y lo no-viviente:

[...] habría que creer, al menos, en la permanencia de los fenómenos naturales, aunque la mutación fuese su constante. (Tarazona, 2011:63)

La tormenta me enseñó el sentido de mis mutaciones. La naturaleza no tiene fallas, sus manifestaciones son signos de adaptación. (Tarazona, 2011: 69)

El desdibujamiento de la frontera entre lo humano y lo animal, que la mujer expresa en su carácter más extremo, involucra también a otros personajes: el hombre, el compañero, tiene unas facciones que apenas existen, y Lisandro es, pese a su nombre, un oso hormiguero que actúa como perro.

Hay en la nouvelle de Tarazona un intercambio de miradas entre la mujer que muta y los otros, sea su compañero, el oso hormiguero o un lisiado con el que se cruza. Todos perciben "algo” en ella. En "¿Por qué mirar a los animales?", John Berger (2001) dedica un espacio importante de su reflexión al intercambio de miradas entre ser humano y animal. El animal, dice, mira a todas las especies del mismo modo, no guarda para el hombre una mirada particular: "Pero ninguna otra especie más que el hombre reconoce como familiar la mirada del animal", entre uno y otro hay "un precipicio de estrecha comprensión" (Berger, 2001: II). Para Berger, la vida humana y la vida animal transcurren paralelas, y convergen en la muerte, aunque el animal le devuelve al humano una comprensión de sí que en el libro de Tarazona reaparece como un "saber" sobre el cambio y la mutación.

\footnotetext{
${ }^{14}$ Véase el trabajo de Graciela Speranza (2017) sobre las ficciones sin tiempo en la estética reciente en Cronografías. Arte y ficciones de un tiempo sin tiempo.
} 
El animal sobre la piedra mantiene en segundo plano, con sutileza, la posibilidad de la mutación de la mujer como patología, probablemente psicológica. Aunque tributando al régimen de doble interpretación de la literatura fantástica que estudió Tzvetan Todorov, claramente Tarazona desborda la incertidumbre fantástica entre una y otra interpretación. Al contrario, la sugerencia de que madre y hermana de la protagonista serían seres en mutación que no se habrían desarrollado plenamente, contribuye a insinuar una inmortalidad de especie que también es la propia del animal. Tal como señala John Berger (2001), los animales serían inmortales en tanto especie, en la medida en que esa inmortalidad supone siempre la renuncia a la individuación del sujeto humano.

En este punto, la evolución vital de la narración de Tarazona se cruza con la transmigración del relato de Schweblin, porque en ambas la apuesta de inmortalidad apareja una dilución del sujeto. Es lo que se reafirma en el desenlace de El animal sobre la piedra, cuando no hay certeza, y es la indeterminación crucial del relato, si el personaje ha gestado otro de su especie o si ella misma es la que ha emergido, animal pleno, del huevo una vez desovado. La posibilidad ya estaba anticipada: "quizás despierte un día de estos dentro de un cascarón: yo dentro de un huevo, cerca del nacer. Quizás mi familia eran una especie extraña y no lo supe." (Tarazona, 2011: 44). La inmortalidad de la especie es ese nacimiento que se engendra - y que quedó trunco en la hermana, y, tal vez, en la madre- en que el descendiente puede ser otro, pero también es la propia mutación. La consideración del ser humano como especie, recordemos, se explicita en las tesis de Dipesh Chakrabarty (2009) que mencioné anteriormente; por otra parte, la fusión del animal y la piedra del título sintetiza un modo de vida pre o post-humano -es imposible definirlo-que erradica a lo propiamente humano, o al menos lo dispone ante una temporalidad más amplia.

Resulta fundamental señalar que la novela de Tarazona está muy lejos de narrar una mutación angustiante y celebra, por el contrario, la plenitud de un devenir animal. Sin embargo, no quiero abandonar este análisis sin sugerir un ángulo de lectura diferente. En Fenomenología del fin, Franco "Bifo" Berardi analiza los modos en que la "mutación digital está invirtiendo la manera en la que percibimos nuestro entorno y también la manera en la que lo proyectamos. No involucra únicamente nuestros hábitos, sino que afecta, a la vez, nuestra sensibilidad y sensitividad." (Berardi, 2017: 10) En su reflexión sobre las enfermedades del nuevo siglo, Berardi entiende que la saturación sin límites del entorno mediático trastorna la razón humana, y reconoce que una radical mutación antropológica se está produciendo debido a la erosión de las capacidades para detectar lo indetectable, para leer los signos invisibles y experimentar empatía en relación con el sufrimiento o el placer del otro:

El universo de receptores (seres humanos hechos de carne y de órganos frágiles y sensuales) no está formateado de acuerdo con los estándares de los transmisores digitales. Aunque el sistema nervioso es sumamente plástico y puede mutar al ritmo de la infoesfera [universo de transmisores], el formato del transmisor no se corresponde con el del receptor. ¿Entonces qué sucede? A medida que el universo electrónico de transmisores interactúa con el mundo orgánico de receptores, produce efectos patológicos: pánico, sobreexcitación, hiperactividad, trastorno por déficit de atención, dislexia, sobrecarga de información y saturación de los circuitos neuronales (Berardi, 2017: 48).

Esta diferencia insalvable entre los ritmos de evolución de lo humano y de las máquinas, subraya Berardi, está ligada a las psicopatologías contemporáneas que, por esa razón, muchos consideran cronopatologías. ¿Qué aporta la reflexión de Berardi a la lectura de la ficción de Tarazona? Para empezar, la contracción de temporalidad y de sensibilidad que identifica Berardi coincide, justamente, con la que experimenta el personaje de la novela. Sin embargo, en la narración este agotamiento deriva en una evolución que la irradia de lo humano: cambia de piel, se ensancha a una experiencia de especie, encarnando su corporalidad y su voz interior de un modo que erradica los polos animal/humano como opuestos o simplemente diferentes. "Fábula" es el título del capítulo que cierra el libro, un nombre que alude menos a un devenir animal que a una modificación de la subjetividad, como consecuencia o como resistencia al agotamiento psíquico y sensorial que expone Berardi. En esta lectura, aquello que permanece en los márgenes de la novela -la experiencia psicopatológica, que se circunscribe a la hermana suicida y al mundo que el personaje abandona- descalifica una interpretación de la mutación como "metáfora" de crisis identitaria y sufrimiento psíquico; se subraya, por el contrario, la mutación como examen de modos de vida potenciales, lo que 
Braidotti (2009) denomina "devenires nómades" en una hipotética experiencia transhumana, ${ }^{15}$ un proceso que ya habría comenzado y que sería, además, inevitable.

\section{Los mundos pegajosos de Mariana Enríquez}

El tercer panel del tríptico de delirios de descomposición que estoy desplegando se basa en la lectura de algunos cuentos incluidos en Las cosas que perdimos en el fuego (2016). La narrativa de Enríquez ha sido inicialmente leída por la crítica como expresión de un gótico urbano, una talentosa renovación del género de la literatura de terror en Latinoamérica que, en efecto, confronta a sus lectores con una experiencia de lo raro y lo espeluznante. Un rasgo que diferencia cabalmente su escritura en relación con las novelas de Schweblin y de Tarazona reside en el tratamiento realista con que la narradora asume los márgenes de la ciudad, un realismo inicial, muy acentuado, que prontamente se desborda hacia sucesos extraordinarios. De tal modo, sus narraciones proponen el desbordamiento entre mundos -uno más visible y otro menos- bajo una estrategia de contraste. En "El chico sucio", para dar un ejemplo, la narradora es una mujer de clase media que se injerta en el territorio marginal de Constitución donde, bien que "refugiada" en su antigua casa familiar, convive con travestis, lumpenaje, migrantes, jóvenes adictos y niños de la calle. Habitante y ajena, la narradora explora el territorio en torno a su casa al tiempo que desarrolla estrategias para recorrerlo y habitarlo. El chico sucio que da título al cuento es uno de los clásicos monstruos que circulan en la narrativa de Enríquez, inequívocos monstruos de clase, sujetos vulnerables, seres a la intemperie particularmente ininteligibles para la narradora, que lo quisiera "un chico amable y encantador, no este chico hosco y sucio" (Enríquez, 2016: 16).

Los personajes de Enríquez son sujetos que la ciudad y sus moradores invisibilizan, pero que aquí imponen su presencia, con desparpajo calculador, incluso con malicia:

Que debe tener unos cinco años, no va a la escuela y se pasa el día en el subterráneo, pidiendo dinero a cambio de estampitas de San Expedito. Lo sé porque una noche, cuando volví a casa desde el centro, lo vi en el vagón. Tiene un método muy inquietante: después de ofrecerles las estampitas a los pasajeros, los obliga a darle la mano, un apretón breve y mugriento. Los pasajeros contienen la pena y el asco (Enríquez, 2016: 12).

O sobre la madre embarazada del chico: "Estaba tan cerca que le veía cada uno de los dientes, cómo le sangraban las encías, los labios quemados por la pipa, el olor a alquitrán en el aliento" (20).

A diferencia del posicionamiento en el devenir que establecen las ficciones de Tarazona y de Schweblin, los cuentos de Enríquez se posicionan en un presente que ya está aquí, y lo hacen de un modo que el registro realista subraya y comprueba. Por eso, los monstruos que aparecen, incluso cuando regresan o devienen, sobre todo son, habitan las grietas de la ciudad, controlan territorios específicos, pululan en parches urbanos henchidos de niños de la calle y madres drogadictas, de encías sangrantes, flacas, con los vientres hinchados y prestas a parir demonios.

Volviendo a "El chico sucio", cuando la narración se hace eco de los rumores sobre sacrificios a San La Muerte, y aparece un niño degollado, la narradora teme que la víctima sea su "vecino", a quién la madre habría entregado al sacrificio. Es lo que luego se confirma, en el frágil rango de confirmación que el cuento provee: la madre no solo ha entregado al niño, también al bebé que esperaba.

El mismo registro de relato alucinatorio vibra en "Bajo el agua negra". En este caso, el sujeto ajeno es una fiscal que investiga la muerte de un chico de la villa arrojado al Riachuelo, probablemente a manos de la policía que lo obligó a "nadar" en el río. ${ }^{16}$ La villa es tierra de nadie, una zona de sacrifico que produce niños deformados, bajo un molde de violencia análogo al que engendra el campo agrotóxico en Distancia de rescate:

\footnotetext{
15 “A través de la teoría de los devenires nómadas o el plano de inmanencia, se disuelve al sujeto y se vuelve a colocar en una ecofilosofía de pertenencias múltiples. Esto implica un decidido énfasis en los elementos prehumanos y hasta no humanos que componen la red de fuerzas, intensidades y encuentros que contribuyen a la formación de la subjetividad nómada. El sujeto es una entidad ecológica.

Zoé se refiere a la vitalidad eterna de la vida como continuo devenir. Guattari y Simondon afirman que este proceso es una forma transversal de subjetividad o "transindividualidad"'. (Braidotti, 2009: 66)

${ }^{16}$ Cabe señalar que los casos de menores asesinados por la policía en esas condiciones se repitieron en Argentina en numerosas ocasiones. Ezequiel Demonty, de 19 años, murió en el 2002 ahogado en el Riachuelo. La muerte de Santiago Maldonado, ahogado en el río Chubut durante un operativo de gendarmería en el 2017 , podría haber sucedido bajo condiciones similares.
} 
Los hijos de las familias que vivían cerca de esa agua, que la tomaban, aunque sus madres intentaban quitarle el veneno hirviéndola, se enfermaban, morían de cáncer en tres meses, horribles erupciones en la piel les destrozaban brazos y piernas. Y algunos, los más chicos, habían empezado a nacer con malformaciones. Brazos de más (a veces hasta cuatro), las narices anchas como de felinos, los ojos ciegos y cerca de las sienes. No recordaba el nombre que los médicos, algo confundidos, le habían dado a ese defecto de nacimiento. Recordaba que uno de ellos lo había llamado "mutaciones" (Enríquez, 2016: 159).

En el desenlace, la fiscal y un cura villero quedan atrapados en un equívoco culto al chico ahogado, vivo y muerto, que ha regresado del agua y que los villeros pasean en procesión. Aquello que regresa irrumpe en la ficción con fuerza apocalíptica y se anuncia en el muerto-mutado que sueña y en las aguas del Riachuelo que se agitan, como si respiraran, en una crecida improbable de su caudal estancado. Interesa subrayar que los nuevos cultos constituyen un leitmotiv de los cuentos de Enríquez, que articula allí narrativamente un espacio de transgresión y resistencia popular, pero también la evidencia o la expresión de superficie de una fuerza ininteligible que conjuga tanto creencias y potencias de los débiles como las zonas descarnadas e irracionales de un colectivo secreto que liga a lo animal y a la especie.

Como otros cuentos de Enríquez, este relato se amplía bajo la clave de lo ominoso, en este caso y en particular, en el regreso del residuo social, de seres que acechan y que el sistema ha denegado. Sin embargo, más que en términos de umheimlich freudiano, resulta estimulante pensar en lo espeluznante tal como lo concibe Mark Fisher (2018), una mirada de y desde lo exterior. Lo espeluznante promueve la pregunta por la naturaleza que provocó una acción, e independientemente del nivel psicoanalítico, nos dirige hacia otra dimensión también medular en la obra de Enríquez:

teniendo en cuenta que lo espeluznante es un aspecto clave en el problema de quién o qué realiza la acción, está muy relacionado con las fuerzas que rigen en el mundo y nuestras propias vidas. Debería quedar especialmente claro a aquellos que vivimos en un mundo capitalista globalmente interconectado que tales fuerzas no son del todo accesibles a nuestra aprehensión sensorial. Una fuerza como el capital no existe en ningún tipo de sentido sustancial, pero es capaz de provocar efectos de casi cualquier tipo. En otro campo, ¿acaso no nos mostró Freud hace ya mucho tiempo que las fuerzas que rigen nuestra psique pueden considerarse como no presencias - ¿no es acaso lo inconsciente una ausencia de presencia? - o no ausencias (las diversas pulsiones o compulsión que interceden allí donde debería actuar nuestro libre albedrío)? (Fisher 2018: 78-9).

En efecto, el capital, sustrato fundamental de la narrativa de Enríquez, como fuerza espeluznante que rige la sociedad capitalista contemporánea es una entidad que "a pesar de surgir de la nada" ejerce "más influencia que cualquier entidad supuestamente sustancial" (Fisher, 2018: 13). En el desenlace, el Riachuelo como fuerza viva determina esta capacidad "intencional" de la naturaleza social degradada, de algún modo, haciéndose eco de la ruptura de fronteras entre lo humano, el cuerpo social y la naturaleza, posicionando una compleja red donde confluyen objetos y sujetos sometidos a un impulso donde la pregunta por las intencionalidades parece subsumida. ${ }^{17}$

En otros cuentos del volumen, "Verde rojo anaranjado" y en "Nada de carne sobre nosotros", lo espeluznante, por el contrario, resulta claramente ligado a las patologías contemporáneas. Estos cuentos son narraciones de casos: en el primero, un joven internauta permanece encerrado en su casa, convertido en ejemplar argentino de los hikikomori japoneses, obsesionado por el internet profundo donde se venden armas, droga, sexo y espectáculos de tortura. En el segundo cuento, la patología depresiva de aislamiento surge en una chica que, por el camino de la inanición, aspira a convertirse en esqueleto. Ambas narraciones extreman patologías contemporáneas, la adicción al internet y la anorexia, representando en espacios urbanos de encierro el avance de una amenaza interior, psíquica e indeterminada, que se alimenta de seres que devienen incorpóreos, lábiles, inmaterialidad pura. Sin embargo, en la narrativa de Enríquez la presentación de estas patologías es inequívocamente social y colectiva. Aunque los personajes se aíslen, en sus patologías hay un movimiento, una transmisión que Sara Amhed (2017) identifica arteramente con los afectos que circulan entre los cuerpos y entre cuerpos y objetos. Terror y atracción circulan entre la narradora y el novioamigo que se encierra en su habitación, en las señales de internet que indican si se encuentra o no conectado,

${ }^{17} \mathrm{Al}$ referirse a Gaia y a las inminentes devastaciones que puede producir el cambio climático, Isabelle Stengers (2007) señala, justamente, que en este caso no hay intencionalidad sino pura acción, una variación de lo que Fisher (2018) identifica con lo espeluznante. 
en la comida que la madre coloca en su puerta ("Verde rojo anaranjado") o en ese nosotros formado por la joven y el cráneo ("En nada de carne sobre nosotros"). Regresando a los cuentos anteriores, también lo que circula está en la dimensión de repugnancia que provoca el chico sucio, los niños mutados o el muerto vivo que sueña. Esa repugnancia establece un circuito de deseo y de rechazo que, tal como señala Sara Amhed (2017) en "La performatividad de la repugnancia", separa los cuerpos en la misma medida en que los atrae, porque supone una relación entre repugnancia y pegajosidad. Para Sara Amhed, la repugnancia es menos un estado que se experimenta, un estado de ánimo o de emoción, que un trabajo sobre la superficie de los cuerpos, una pegajosidad latente que resulta explícita en el fragmento inicial que ya cité de "El chico sucio", donde el niño fuerza a los viajeros del subte a darle la mano. "Tal vez, la pegajosidad se vuelve repugnante solo cuando la superficie de la piel está en juego, de modo que lo pegajoso amenaza con quedársenos pegado (Amhed, 2017: 144), subraya Amhed.

\section{Delirios imaginativos versus imaginaciones devastadas}

"Las cosas que perdimos en el fuego" está entre los más perturbadores cuentos de Enríquez. Motivado por los casos de feminicidios, entre otros, el de Wanda Taddei en 2010 (Alejandra Oscari en 2017 y Graciela Ibarra en 2018 son posteriores a la publicación), propone una organización de Mujeres Ardientes que se queman por propia decisión para imponer su presencia de pieles quemadas a una sociedad que cierra los ojos al acoso y a los feminicidios. En la narración, nada puede detener las quemas clandestinas, los hospitales de tratamiento de quemadas, mujeres que no se arrepienten, que entran en el fuego "como en una pileta de natación" (193) convulsionando una mutación de la que surge el horror de una nueva belleza:

hacía apenas semanas, las primeras mujeres sobrevivientes habían empezado a mostrarse, a tomar colectivos. A comprar en el supermercado. A tomar taxis y subterráneos, a abrir cuentas de banco y disfrutar de un café en las veredas de los bares, con las horribles caras iluminadas por el sol de la tarde, con los dedos, a veces sin algunas falanges, sosteniendo la taza. ¿Les darían trabajo? ¿Cuándo llegaría el mundo ideal de hombres y monstruas? (Enríquez, 2016: 195-6).

Estas "monstruas", con su dimensión de engendro y de reivindicación lingüística, constituyen la cara sumergida, y ahora llevada a la superficie de la piel, de una mutación femenina que dialoga con el devenir reptil de la mujer de Tarazona y el devenir fantasma en la novela de Schweblin. Probablemente, "pese" el giro fantástico que atraviesa siempre su prosa, Enríquez sea quien con mayor énfasis subraya las condiciones materiales y políticas, históricas y geográficas de la degradación del neoliberalismo contemporáneo, que en las otras narradoras adquiere una tonalidad más globalizada, igual de efectiva, pero menos anclada en un lugar-tiempo.

Por otra parte, la exploración de maternidades o gestaciones alternativas se reitera en las tres ficciones. En el caso de Tarazona, la exteriorización de la procreación se escenifica cuando la mujer reptil se apoya en el semen que el hombre ha lanzado sobre la piedra, en un cuadro que tipifica formas alternativas de procreación y que, en esta novela, desemboca en una gestación ovípara. Además, tanto en Tarazona como en Schweblin, sea en los cuerpos que transmutan, se dividen y fragmentan, o sea en la ampliación de los sujetos y del relato de especie, se subvierte la maternidad entendida como una relación de dos (en el caso de Schweblin, la lucha de la madre moribunda escenifica una resistencia a esa ruptura, pero también una admisión de incapacidad para proteger al hijo en esas condiciones). Lo menos que puede decirse es que la exploración de configuraciones divergentes de la reproducción y de la gestación introduce experiencias materiales que impactan sobre las ideologías de género. En ese sentido, mientras que, inicialmente, el texto de Schweblin ancla la noción de futuro en la figura del Niño, la de Tarazona lo hace en una gestación alternativa que introduce una fractura en la propagación de lo mismo que implica la procreación. Pero también en "Las cosas que perdimos en el fuego", en donde la protagonista narra justamente el activismo de su madre en "Mujeres ardientes" y lo que tal vez será su propio re-nacimiento como quemada, se alude a una práctica de creación de monstruas que es, en definitiva, un nuevo colectivo de mutadas, una gestación que requiere y surge de dinámicas colectivas. La hipótesis de un futuro desviado por la tecnología del fuego, esta vez implementado por un colectivo de disidentes, constituye una apropiación de las prácticas de acoso y sojuzgamiento, pero sobre todo constituye una apuesta por corporalidades y experiencias vitales heterogéneas e insospechadas. En definitiva, en todas las ficciones la responsabilidad en relación con "los que vendrán" transciende ampliamente las fronteras del cuidado restringido al ámbito familiar y postula en su lugar derechos-cuidado y ética en un plano colectivo. 
Por último, quiero detenerme en el delirio ficcional que en mayor o menor medida instalan estas narraciones. El delirio no está definido aquí como patología sino como un modo divergente de imaginación, lo que Deleuze (1996) liga con la virtualidad en Crítica y Clínica, ese "Objetivo último de la literatura: poner de manifiesto en el delirio esta creación de una salud, o esta invención de un pueblo, es decir una posibilidad de vida. Escribir por ese pueblo que falta («por» significa menos «en lugar de» que «con la intención de»)" (Deleuze, 1996: 17). Hay que entender que las ficciones contemporáneas están empapadas del ánimo de derrota frente al avance necropolítico y la hecatombe planetaria, un ánimo que expresa cierta "sensación de época", también ellas se confrontan con la ausencia de soluciones o caminos opcionales y con la incertidumbre de una denuncia que parece de más en más inútil. Por eso, en franca oposición al dogma neoliberal de que no hay alternativas, estas ficciones reivindican su delirio al pergeñar formas de vida alternativa, incluso sin alcanzar a definirlas por completo. Cuando las tramas potencian cuerpos desmaterializados, estos abandonan su forma sin que logremos conocer con certeza lo que ha surgido en su lugar. De cara a la agresión y al agotamiento vital que alcanza los territorios, pero también es atinente a los cuerpos, y frente a una política de vidas sacrificables que se "sincera" en el establecimiento de las llamadas "zonas de sacrificio" - como puede ser el campo bajo los agrotóxicos en Distancia de rescate o las villas y márgenes de las violencias sistémicas de la necropolítica en Enríquez- estas narraciones denuncian la emergencia de una amenaza a escala planetaria.

En síntesis, los desenlaces de estas narraciones se abren a un tránsito que escapa de sus propias condiciones de aparición y avanza, con paso trémulo, hacia un terreno especulativo, el registro del delirio (es delirio lo que supone o practica Daniel, el niño-fantasma que habla con la mujer moribunda en Distancia de rescate; sería delirio lo que imagina o vive la mujer iguana, y hay un delirio intrínseco en el universo de los cuentos de Enríquez, sitiado por eso espeluznante que espera en un exterior siempre adyacente, que no solo está destinado a regresar o devenir, sino que se pegará a la piel de los sujetos que quieran escapar). La radicalidad de estos delirios estriba también en su imposibilidad de nombrar o concebir aquello que sugieren. Bajo esa restricción, las narraciones reiteran la indeterminación del origen de las voces o de los parámetros desde donde estas voces establecen sus actos de habla. Lo que comunican está poblado de ruidos que perturban una comunicación eficiente, $\mathrm{y}$ emergiendo de ese ruido fundante, una silueta toma forma, deslocalizada por el trance o el movimiento, en el rango innombrable de finales abiertos, enigmáticos, que señalan un más allá del desenlace. Tal como indica Toni Navarro al presentar el libro de Helen Hester (2018), la amenaza de un colapso particularmente en el plano ecológico, pero no solamente en ese plano, ha revitalizado "la tarea de inventar el futuro -otro de los temas que ha cobrado fuerza en el pensamiento contemporáneo, y que coincide con el auge de la ciencia ficción en el cine y la literatura-.” (10).

¿Pero qué es lo que anticipan estas ficciones?, ¿qué estarían anticipando, o más bien promoviendo y explorando, de un modo errático o impronunciable? La respuesta vislumbra una mutación corporal, sensible, cognitiva, la desterritorialización de la noción misma de sujeto y de comunidad. La ampliación de lo que puede ser experimentado, que es propia de lo político y de lo poético, constituye el motor secreto de estos delirios de descomposición. ${ }^{18}$ Stengers (2007) se refiere al pánico frío que el sujeto contemporáneo experimenta ante la falta de opciones, un estado de virtual suicidio colectivo impulsado por un "progreso" imposible de detener. Resulta paradójico en este contexto, el arte y la literatura en particular regresen para nombrar o, más precisamente, articular imaginaciones de lo imposible en virtud de "repoblar el desierto devastado de nuestras imaginaciones" (Stengers, 2007: 130).

\section{Referencias bibliográficas}

Amhed, Sara (2017). La política cultural de las emociones. Ciudad de México: Programa Universitario de Estudios de Género de la UNAM.

Andermann, Jens (2011), "Tesis sobre la metamorfosis", Aletria. Revista de Estudos de Literatura, vol. 21, nº. 3, págs. $154-164$

$$
\text { pesados. }
$$

- (2018). Tierras en Trance: Arte y naturaleza después del paisaje. Santiago de Chile: Metales

\footnotetext{
${ }^{18}$ Incluso un libro teórico, como el Berardi (2017), se cierra bajo un tono especulativo que discrepa de su perspectiva pesimista en relación con el desgaste de la sensibilidad humana ante la mutación digital. Su reflexión en torno a la posibilidad -su deseo- de que la neuroplasticidad genere una reorganización autónoma del aparato psicocognitivo avanza en el plano de la utopía o de la invención poética.
} 
Bauman, Zygmunt (2004). Modernidad líquida. Buenos Aires: Fondo de Cultura Económica.

Berardi, Franco (2017). Fenomenología del fin. Sensibilidad y mutación colectiva. Buenos Aires: Caja negra.

Berger, John (2001), "¿Por qué nos miran los animales?", El jarocho verde, nº. 13-14, I-X.

Braidotti, Rosi (2009). Transposiciones. Sobre la ética nómada. Barcelona: Gedisa.

Chakrabarty, Dipesh (2009), "Clima e historia: cuatro tesis", Pasajes: revista de pensamiento contemporáneo, 31, págs. 51-69.

Crary, Jonathan (2015). 24/7. El capitalismo tarío y el fin del sueño. Buenos Aires: Paidós.

Deleuze, Gilles (1996). Crítica y clínica. Barcelona: Anagrama.

Deleuze, Gilles y Felix Guattari (2002). Mil mesetas. Capitalismo y esquizofrenia. Valencia: Pretextos.

Enríquez, Mariana (2016). Las cosas que perdimos en el fuego. Buenos Aires: Anagrama.

Fisher, Mark (2018). Lo raro y lo espeluznante. Barcelona: Alpha Decay.

Giorgi, Giorgi (2014). Formas comunes. Animalidad, cultura, biopolìtica. Buenos Aires: Eterna Cadencia.

Hester, Helen (2018). Xenofeminismo. tecnologías de género y políticas de reproducción. Buenos Aires: Caja Negra.

Nancy, Jean-Luc (2007). 58 indicios sobre el cuerpo, Extensión del alma. Buenos Aires: Ediciones La cebra.

Rosa, Harmut (2011), "Aceleración social: consecuencias éticas y políticas de una sociedad de alta velocidad desincronizada", Persona y Sociedad 9, vol. XXV / nº. 1 , págs. 9-49.

Schweblin, Samanta (2014). Distancia de rescate. Buenos Aires: Random House.

Sibilia, Paula (2006). El hombre postorganico: cuerpo, subjetividad y tecnologias digitales. Buenos Aires: Fondo de Cultura Económica.

Speranza, Graciela (2017). Cronografías. arte y ficciones de un tiempo sin tiempo. Barcelona: Anagrama.

Stengers, Isabelle (2007). En tiempos de catástrofes. Cómo resistir a la barbarie que viene. Barcelona: Ediciones Ned.

Tarazona, Daniela (2011). El animal sobre la piedra. Buenos Aires: Entropía.

Todorov, Tzvetan (1982). Introducción a la literatura fantástica. Barcelona: Ediciones Buenos Aires. 